\title{
Methyl- $\beta$-cyclodextrin alters growth, activity and cell envelope features of sterol-transforming mycobacteria
}

\author{
Correspondence \\ M. V. Donova \\ donova@ibpm.pushchino.ru
}

Received 22 August 2006

Revised 16 January 2007

Accepted 17 February 2007

\author{
M. V. Donova, V. M. Nikolayeva, D. V. Dovbnya, S. A. Gulevskaya \\ and N. E. Suzina
}

G. K. Skryabin Institute of Biochemistry and Physiology of Microorganisms, Russian Academy of Sciences, 142290, Pushchino, Moscow Region, Russia

\begin{abstract}
Modified $\beta$-cyclodextrins have been shown previously to enhance sterol conversion to 4-androstene-3,17-dione (AD) and 1,4-androstadiene-3,17-dione (ADD) by growing Mycobacterium spp. The enhancement effect was mainly attributed to steroid solubilization by the formation of inclusion complexes with modified cyclodextrins. In this work, the influence of randomly methylated $\beta$-cyclodextrin (MCD) on the growth, AD- and ADD-producing activity, cell wall $(\mathrm{CW})$ composition and ultrastructure of sterol-transforming Mycobacterium sp. VKM Ac-1816D was studied. The specific growth rate of the strain on glycerol increased in the presence of MCD (20-100 mM). Washed cells grown in the presence of MCD (20-40 mM) expressed 1.6-fold higher ADD-producing activity than did the cells grown without MCD, and their adhesiveness differed. Electron microscopy showed MCD-mediated CW exfoliation and accumulation of membrane-like structures outside the cells, while preserving cells intact. The analysis of CW composition revealed both a decrease in the proportion of extractable lipids and a considerable shift in fatty acid profile resulting from MCD action. The MCD-mediated enhancement of mycolic and fatty acids content was observed outside the cells. The total secreted protein level rose 2.4-fold, and the extracellular 3-hydroxysteroid oxidase activity 3.2-fold. The composition of the CW polysaccharide was not altered, while the overall proportion of the carbohydrates in the CW of the MCD-exposed mycobacteria increased. The results showed that the multiple mechanisms of MCD-mediated intensification of sterol to AD(D) conversion by mycobacteria include not only solubilization of steroids, but also the increase of $\mathrm{CW}$ permeability for both steroids and soluble nutrients, disorganization of the lipid bilayer and the release of steroid-transforming enzymes weakly associated with the $\mathrm{CW}$.
\end{abstract}

\section{INTRODUCTION}

Mycobacteria are distinct from other Gram-positive bacteria in the unique composition of their cell wall (CW) (Draper, 1982; Bendinger et al., 1993). The basal CW skeleton is composed of chemotype IV peptidoglycan, which is covalently linked to the mycolyl arabinogalactan and lipoarabinomannan (Brennan \& Nikaido, 1995). It is covered by an asymmetric lipid bilayer that non-covalently binds with the arabinogalactan/peptidoglycan (Minnikin, 1991; Nikaido \& Jarlier, 1991; Chatterjee, 1997). The internal leaflet of this bilayer is composed of tightly packed mycolic acids that

Abbreviations: AD, 4-androstene-3,17-dione; ADD, 1,4-androstadiene3,17-dione; AGM, amorphous granular material; $C D$, cyclodextrin; CPM, cytoplasmic membrane; CW, cell wall; Dimeb, dimethylated $\beta$-cyclodextrin; DHEA, dehydroepiandrosterone; FAMEs, fatty acid methyl esters; IL, electron-dense internal layer; MAMEs, mycolic acid methyl esters; MCD, randomly methylated $\beta$-cyclodextrin; MLS, membrane-like structures; $\mathrm{OL}$, low-contrasting outer layer; TL, electron-transparent layer. extend perpendicularly to the arabinogalactan/peptidoglycan. The leaflet is of low fluidity and combined with arabinogalactan. The mycolic acids of this layer are mostly branched fatty acids with a $\mathrm{C}_{40}-\mathrm{C}_{60}$ long chain and a $\mathrm{C}_{22}-\mathrm{C}_{24}$ short chain containing a relatively low amount of double bonds or cyclopropane groups. The outer leaflet of the bilayer consists of extractable lipids: phospholipids, trehalose-containing glycolipids, peptidolipids and mycosides. It was shown that the outer leaflet of the asymmetric bilayer is of moderate fluidity, while the mycolic acid-containing inner leaflet is of extremely low fluidity, thus accounting for the low CW permeability (Liu et al., 1996). In general, the mycobacterial CW can contain up to $60 \%$ lipids, which determine its extremely high hydrophobicity and low permeability. This results in relatively slow growth, multiple drug resistance, high cell-to-cell adhesiveness and the formation of cell agglomerates (Jarlier \& Nikaido, 1994; Borrego et al., 2000).

As shown for a few pathogenic mycobacteria and related organisms, the CW can be surrounded by a capsule-like 
structure consisting of polysaccharides, proteins and lipids (Daffé \& Draper, 1998). This capsule can cover one or a few cells, forming a so-called 'core-factor'. Under laboratory conditions, mycobacteria are usually cultivated with vigorous shaking in the presence of detergents, thus resulting in the destruction of the capsule. The capsule-like structures of mycobacteria are electron-transparent zones surrounding the $\mathrm{CW}$, and their identification by standard-practice electron microscopy can be problematic. No data on the capsule-like structures of saprophyte non-pathogenic mycobacteria have been reported, except for the noting of the possible difference in capsule composition of slow- and fast-growing mycobacteria (Daffe \& Draper, 1998).

The composition, lipid content and features of the mycobacterial CW depend on the physiological stage and cultivation conditions (temperature, carbon and nitrogen source, etc.) (Ratledge, 1982; Lacave et al., 1990). For instance, cells grown on glycerol or fructose are more hydrophobic than those grown on glucose (Borrego et al., 2000).

There are three possible routes for influx of organic molecules into the mycobacterial cell. Water-soluble nutrients and small hydrophilic molecules enter through the water-filled channels composed of pore-forming proteins, as described for Mycobacterium chelonae and Mycobacterium smegmatis (Trias et al., 1992; Trias \& Benz, 1994). The second, so-called 'lipid' pathway, is generally used for lipophilic and amphiphilic agents, while the third pathway, 'self-promoted uptake', mostly provides the entrance for polycation compounds and aminoglycosides (Trias \& Benz, 1994).

Steroids can cross the mycobacterial CW by the 'lipid' pathway. It was proposed that they dissolve in the lipid domain and 'redissolve' in the aqueous phase on the outer side of the cell (Nikaido \& Jarlier, 1991). The lipid bilayer, as well as other constituents of the $\mathrm{CW}$, can present a penetration barrier for these uncharged compounds.

Different approaches were applied to increase the permeability of the CW for steroids. As shown for Mycobacterium vaccae and relative strains, CW permeability for androstane steroids is promoted by vancomycin (Lisowska et al., 1996), glycine (Sedlaczek et al., 1999), lecithin (Rumijowska et al., 1997) and polycations (protamine, polymyxin B nonapeptide and polyethyleneimine) (Korycka-Machala et al., 2001). The inhibition of peptidoglycan synthesis by glycine $\left(15 \mathrm{mg} \mathrm{ml}^{-1}\right)$ and vancomycin $\left(150 \mu \mathrm{g} \mathrm{ml}^{-1}\right)$ resulted in substantial enhancement of sitosterol conversion (Sedlaczek et al., 1994). These agents interacted with the CW peptidoglycan and shifted the ratio of muramic and diaminopimelinic acids (Lisowska et al., 1996; Sedlaczek et al., 1999). Glycine was shown to alter the ratio of mycolic acids to other lipids. Lecithin influenced the fatty acid profile of the $\mathrm{CW}$, thus resulting in greater 4-androstene-3,17-dione (AD) and 1,4-androstadiene-3,17dione (ADD) formation from sitosterol (Rumijowska et al., 1997). Protamine altered the content of non-covalently bound lipids in the outer leaflet of the lipid bilayer, shifted the ratio of fatty acids and influenced the integrity and fluidity of the bilayer. This effect also resulted in a considerable increase in $\mathrm{AD}(\mathrm{D})$ productivity (KoryckaMachala et al., 2001). Fluorophenylalanine and DL-norleucin affected the biosynthesis of amphipathic components of the outer lipid bilayer, thus enhancing sterol to $\mathrm{AD}(\mathrm{D})$ bioconversion by $M$. vaccae. In contrast, the structural alterations of mycolyl arabinogalactan by ethambutol ( $40 \mu \mathrm{g}$ $\mathrm{ml}^{-1}$ ) resulted in the decrease of $\mathrm{AD}(\mathrm{D})$ yield from sitosterol (Sedlaczek et al., 1994). Isoniazid (350 $\left.\mu \mathrm{g} \mathrm{ml}^{-1}\right)$ suppressed the synthesis of mycolic acids, damaged the cell and inhibited sitosterol conversion to $\mathrm{AD}(\mathrm{D})$. Thus, the integrity of the mycolyl-arabinogalactan structure is important for the effective bioconversion of sterol to androstanes.

Cyclodextrins (CDs) are biocompatible cyclic oligosaccharides consisting of a few $\alpha$-1,4-linked glucose units. Their most important property is the capacity to form soluble non-covalent inclusion complexes with lipophilic substances (Fromming \& Szejtly, 1993). This molecular encapsulation can result in significant enhancement of the water solubility of hydrophobic compounds and is widely used in pharmacy, biotechnology, cosmetics and other fields (Szejtli, 1997).

The enhancement effect of native $(\beta-$ and $\gamma-)$ and chemically modified $\beta$-CDs on sterol conversion to $\mathrm{AD}(\mathrm{D})$ by Mycobacterium spp. was described previously (Hesselink et al., 1989; Donova et al., 1996). This effect was mainly attributed to the solubilization of steroids due to the formation of soluble inclusion complexes with CDs. However, the influence of CDs on the mycobacterial cell physiology, probable alterations in CW permeability, cell adhesiveness and other features have not been investigated so far.

For several reasons (solubilizing properties, price, availability, etc.), randomly methylated $\beta$-CD (MCD) is one of the most widely used $\mathrm{CD}$ derivatives in biotechnology. Its application at sitosterol conversion by growing Mycobacterium spp. resulted in significant increase of $\mathrm{AD}(\mathrm{D})$ yield (Donova et al., 1996). The purpose of the present work was to study MCD-mediated alterations in CW composition and the features of the fast-growing Mycobacterium sp. VKM Ac-1816D, capable of producing $\mathrm{ADD}$ as a major product from sitosterol.

\section{METHODS}

Materials. $\beta$-Sitosterol (ultragrade, $91.4 \%$ purity) was obtained from Kaukas, 4-androstene-3,17-dione (AD), 1,4-androstadiene-3,17dione (ADD) and dehydroepiandrosterone (DHEA, 3 $\beta$-hydroxy-5androsten-17-one) were purchased from Sigma, MCD CAWASOL W7 M1.8 from Wacker Chemie, $\mathrm{C}_{12}-\mathrm{C}_{27}$ fatty acids from Supelco, and yeast extract and agar from Difco; other materials were of reagent grade and purchased from domestic companies.

Micro-organisms and cultivation. The non-pathogenic, fastgrowing strain of Mycobacterium sp. VKM Ac-1816D, yielding ADD 
as a major product from sitosterol, was obtained from the All-Russian Collection of Microorganisms (VKM IBPM RAS). A comparison of the strain with Mycobacterium spp. DSMZ 2966 (synonymous with Mycobacterium sp. NRRL 3683B), which is well-known for its steroltransforming activity and is widely used for sterol bioconversion studies by many authors, confirmed the similarity of the two strains. The same patterns of amplification products were obtained for strains Mycobacterium sp. VKM Ac-1816D and Mycobacterium sp. DSMZ 2966 by restriction of the $16 \mathrm{~S}$ rRNA gene and the variable $16 \mathrm{~S}-23 \mathrm{~S}$ rRNA intergenic region with endonuclease Hin6I. Since Mycobacterium sp. NRRL 3683B was reported to be identified as $M$. vaccae (Korycka-Machala et al., 2001), the close relative strain Mycobacterium sp. VKM Ac-1816D most probably also belongs to $M$. vaccae.

The seed culture was prepared in shake flasks, in two consecutive cultivation steps (48 and $24 \mathrm{~h}$ ), in glycerol-yeast extract medium (Donova et al., 1996). Unless otherwise mentioned, the culture was grown in $750 \mathrm{ml}$ shake flasks with $100 \mathrm{ml}$ glycerol-mineral medium containing $\left(\mathrm{g} \mathrm{l}^{-1}\right)$ : glycerol, 5; $\left(\mathrm{NH}_{4}\right)_{2} \mathrm{SO}_{4}, 3 ; \mathrm{MgSO}_{4}, 0.2 ; \mathrm{FeSO}_{4}, 0.01$ and $\mathrm{ZnSO}_{4}, 0.002$ in $0.05 \mathrm{M}$ potassium phosphate buffer $(\mathrm{pH} 7.0$ ), using $10 \%(\mathrm{v} / \mathrm{v})$ of second-step seeds, on a rotary shaker $(200$ r.p.m.) at $30{ }^{\circ} \mathrm{C}$ for $24 \mathrm{~h}$.

To study the CW chemical composition alterations mediated by MCD and/or $\beta$-sitosterol, the glycerol-mineral medium was supplemented with $5 \mathrm{mM} \beta$-sitosterol (S), or $25 \mathrm{mM} \mathrm{MCD} \mathrm{(M),} \mathrm{or} 5 \mathrm{mM} \beta$ sitosterol along with $25 \mathrm{mM}$ MCD (SM). After $30 \mathrm{~h}$ of growth, the cells were separated by centrifugation $(6000 \mathrm{~g})$. The biomass samples and supernatants (post-culture media) were lyophilized and used for $\mathrm{CW}$ chemical composition assays.

Effect of MCD on cell growth and aggregation. The strain was cultivated on glycerol-mineral medium supplemented with 0-180 mM MCD, using $10 \%(\mathrm{v} / \mathrm{v})$ of the second-step seeds taken in the exponential growth phase.

Since cell-clumping due to high CW hydrophobicity hindered preparation of a single-cell suspension, the culture growth was controlled mainly by dry weight estimation. Cultivation broth samples $(5 \mathrm{ml})$ were taken every $3 \mathrm{~h}$, centrifuged for $30 \mathrm{~min}$ at $2000 \mathrm{~g}$ in pre-weighed test tubes, washed with $10 \mathrm{ml}$ of $1 \%(\mathrm{w} / \mathrm{v}) 2$ propanol solution and centrifuged again. The cells were then dried to a constant weight (for $4-6 \mathrm{~h}$ ) at $80{ }^{\circ} \mathrm{C}$ and weighed on precision balances. The experiments were performed with at least three repeats. The culture density values were calculated based on the dry cell weights and plotted vs the cultivation time. Specific growth rates $(\mu)$ were obtained by nonlinear fitting of the model of exponential growth. Additionally, culture broth samples $(1 \mathrm{ml})$ were taken every $9 \mathrm{~h}$, submitted to a serial dilution and $100 \mu \mathrm{l}$ aliquots were plated on glycerol-mineral medium solidified with $2 \%(\mathrm{w} / \mathrm{v})$ agar (Difco). The separate colonies were counted after 7 days incubation at $30{ }^{\circ} \mathrm{C}$.

In order to estimate strain ability to utilize MCD as a carbon source, the cells were incubated with glycerol-free liquid or solidified medium of the same composition supplemented with 40-80 mM MCD.

The culture optical density at $600 \mathrm{~nm}\left(\mathrm{OD}_{600}\right)$ was monitored on a Specord M40 spectrophotometer (Carl Zeiss) after fivefold dilution of the broth aliquots with $0.05 \mathrm{M}$ potassium phosphate buffer ( $\mathrm{pH} 7.0$ ). The aggregation of cells was estimated as a ratio of dry cell weight to $\mathrm{OD}_{600}$ (Borrego et al., 2000).

Steroid permeability estimation. The CW permeability for steroids was estimated as the rate of $\mathrm{AD}(\mathrm{D})$ formation from $\beta$-sitosterol (Korycka-Machala et al., 2001). The strain was grown in medium containing $\left(\mathrm{g} \mathrm{l}^{-1}\right)$ : glycerol, 7.5; $\left(\mathrm{NH}_{4}\right)_{2} \mathrm{SO}_{4}, 4.5 ; \mathrm{MgSO}_{4}, 0.2 ; \mathrm{FeSO}_{4}$, 0.01 and $\mathrm{ZnSO}_{4}, 0.002$ in $0.05 \mathrm{M}$ potassium phosphate buffer $(\mathrm{pH} 7.0$ ), with or without MCD $(0-100 \mathrm{mM})$. To induce sterol-transforming activity, $\beta$-sitosterol $(1 \mathrm{mM})$ was added after $24 \mathrm{~h}$ of incubation as a hot dimethylformamide solution $\left(223 \mathrm{~g} \mathrm{l}^{-1}, 50{ }^{\circ} \mathrm{C}\right)$. After $30 \mathrm{~h}$ of cultivation, the cells were harvested by centrifugation $(5000 \mathrm{~g})$ at $4{ }^{\circ} \mathrm{C}$ for $30 \mathrm{~min}$ and washed twice with $0.05 \mathrm{M}$ potassium phosphate buffer ( $\mathrm{pH}$ 7.0). Sitosterol $(10 \mathrm{mM})$ conversion was carried out using washed cells in $750 \mathrm{ml}$ Erlenmeyer flasks containing $100 \mathrm{ml}$ of the same buffer, on a rotary shaker (200 r.p.m.) at $30{ }^{\circ} \mathrm{C}$. Biomass corresponded to $0.33 \mathrm{~g}$ of dry cells per litre.

Bioconversion broth samples $(2 \mathrm{ml})$ were taken every 3-24 h, diluted with $50 \%(\mathrm{v} / \mathrm{v})$ acetonitrile solution and centrifuged at $2000 \mathrm{~g}$ for $30 \mathrm{~min}$. Steroids were analysed by reverse-phase HPLC on a $250 \mathrm{~mm}$ ODS column using acetonitrile/water $(64: 36, \mathrm{v} / \mathrm{v})$ as eluent $(1 \mathrm{ml}$ $\min ^{-1}$ ) at $50{ }^{\circ} \mathrm{C}$ with UV absorbance detection at $240 \mathrm{~nm}$.

\section{Lipid analyses}

(i) Mycolic and fatty acids. The lyophilized cell samples (100 mg) were treated with $5 \mathrm{ml}$ methyl alcohol/sulfuric acid $(4: 1, \mathrm{v} / \mathrm{v})$ for $18 \mathrm{~h}$ at $75{ }^{\circ} \mathrm{C}$ as described by Sedlaczek et al. (1999). The methyl esters of mycolic (MAMEs) and fatty (FAMEs) acids obtained were extracted three times with hexane and the extracts were combined and filtered using a column with ammonium hydrogen carbonate. The filtrates were evaporated and redissolved for TLC. The aliquots were applied on Merck Silica gel 60 TLC plates, developed in hexane/ethyl acetate $(94: 6, \mathrm{v} / \mathrm{v})$ and visualized by spraying with a $10 \%(\mathrm{w} / \mathrm{v})$ ethanol solution of phosphomolybdic acid, followed by heating for $10 \mathrm{~min}$ at $180^{\circ} \mathrm{C}$. The supernatants $\mathrm{S}$ and SM $(50 \mathrm{ml})$ were also lyophilized and used after methanolysis for mycolic and fatty acid analyses in the same way as described for the cells.

(ii) Free lipids. The non-covalently bound CW lipids were extracted from samples of lyophilized cells (100 $\mathrm{mg}$ each) and lyophilized supernatants $(50 \mathrm{ml})$ with $50 \mathrm{ml}$ of chloroform/methanol $(2: 1, \mathrm{v} / \mathrm{v})$ by vigorous stirring for $36 \mathrm{~h}$ at $30{ }^{\circ} \mathrm{C}$. The residue was separated by filtration, and the filtrate was evaporated and redissolved for TLC. TLC analysis was carried out as described above for fatty acids.

(iii) Fatty acid composition. The composition of fatty acids was determined in methanolysates of the free lipid concentrates obtained as described above. The concentrates $(20 \mathrm{mg}$ for cells grown in SM and S; $150 \mathrm{mg}$ for supernatant SM, $30 \mathrm{mg}$ for supernatant S) were dissolved in acetyl chloride/methanol $(1: 10, \mathrm{v} / \mathrm{v})$ and incubated at $80{ }^{\circ} \mathrm{C}$. Fatty acid analysis was carried out using a Philips PU 4400 gas chromatograph with a flame-ionization detector on an OV-101 capillary column $(0.22 \mathrm{~mm}$ i.d. $\times 30 \mathrm{~m})$ under a temperature gradient from 80 to $320{ }^{\circ} \mathrm{C}$. The temperature of the injector was $340{ }^{\circ} \mathrm{C}$; the detector was at $350{ }^{\circ} \mathrm{C}$. For quantification, standard $\mathrm{C}_{12}-$ $\mathrm{C}_{28}$ fatty acids were used.

Carbohydrate assay. Lyophilized cell samples (20 mg) were hydrolysed in $3 \mathrm{M}$ trifluoroacetic acid at $105{ }^{\circ} \mathrm{C}$ for $3.5 \mathrm{~h}$ in nitrogen-blown and sealed glass ampoules. The acid was evaporated under reduced pressure. The borate carbohydrate complexes (Schimz et al., 1985) were assayed using an LC 2000 carbohydrate analyser (Biotronik) equipped with a Durum DA-X8-11 column. Disodium $4,4^{\prime}$-dicarboxy-2,2'-bisquinoline was used for detection at $570 \mathrm{~nm}$. The amount of individual carbohydrates was estimated using the absolute calibration method.

Other analyses. The samples of supernatants S and SM were concentrated to $1.2 \mathrm{ml}$ using Centricon Plus-20 cartridges (Millipore). The protein content was determined as described by Bradford (1976), using BSA as a standard. The activity of the 3hydroxysteroid oxidase was measured at $37{ }^{\circ} \mathrm{C}$ and $\mathrm{pH} 6.8$ as described by Sojo et al. (1997) and Nikolayeva et al. (2004). The assay mixture contained $100 \mathrm{mM}$ Tris/ $\mathrm{HCl}(\mathrm{pH} 6.8), 15 \mathrm{mM}$ MCD, $1 \mathrm{mM}$ 
DHEA, $7 \mathrm{mM}$ phenol, $4 \mathrm{mM}$ 4-aminoantipyrine and $7.6 \mu \mathrm{g} \mathrm{ml}^{-1}$ peroxidase. The reaction was started by addition of $150 \mu$ sample to $1 \mathrm{ml}$ assay mixture. One unit of activity (U) was defined as the amount of enzyme that converted $1 \mu \mathrm{mol}$ DHEA per min at $37{ }^{\circ} \mathrm{C}$. Steroids were analysed by TLC and HPLC as described earlier (Donova et al., 1996).

Electron microscopy. The cell samples were washed three times with $0.1 \mathrm{M}$ sodium phosphate buffer ( $\mathrm{pH} 7.6)$ and fixed in $1.5 \%$ glutaric aldehyde in $0.05 \mathrm{M}$ cacodylate buffer ( $\mathrm{pH}$ 7.2). In some experiments, the solution contained an additional $0.075 \%(\mathrm{w} / \mathrm{v})$ ruthenium red. The samples were then washed three times with cacodylate buffer (with or without ruthenium red) and fixed with $1 \%$ $\mathrm{OsO}_{4}$ in $0.05 \mathrm{M}$ cacodylate buffer (with or without ruthenium red), dehydrated by serial ethanol dilutions and embedded in Epon 812 or Spurr resin. Ultrathin sections were cut with an LKB-2128 ultramicrotome (LKB), contrasted with a $2 \%$ uranyl acetate solution in $70 \%$ ethanol or uranyl acetate with lead citrate as described by Reynolds (1963), and examined with a JEM-100B electron microscope (JEOL) at an accelerating voltage of $60-80 \mathrm{kV}$.

Freeze-etching. Cell-substrate aggregates were separated by mild sedimentation (without centrifugation). A small amount (one drop) of the sample was placed between the thin copper holders and quenched in liquid propane. The frozen samples were fractured at $-70{ }^{\circ} \mathrm{C}$ in a vacuum of about $1.3 \times 10^{-5} \mathrm{~Pa}$. The fractured samples were etched at $-100{ }^{\circ} \mathrm{C}$ for $3 \mathrm{~min}$ at $1.7 \times 10^{-3} \mathrm{~Pa}$, then replicated with platinum-carbon and backed with about $20 \mathrm{~nm}$ carbon. The replicas were cleaned overnight with chromic acid, washed with distilled water and observed with a JEM-100B electron microscope (JEOL).

\section{RESULTS}

\section{The effect of MCD on the growth and aggregation of mycobacteria}

Absence of growth was observed when Mycobacterium sp. VKM Ac-1816D strain was incubated in glycerol-free mineral medium containing MCD, thus confirming the inability of mycobacteria to utilize MCD as carbon source.

Supplementing the glycerol-containing medium with MCD resulted in a dose-dependent effect on culture growth (Fig. 1a, b). The specific growth rate $(\mu)$ reached a maximum level of $0.094 \mathrm{~h}^{-1}$ in the medium with $80 \mathrm{mM}$ MCD. It was about 1.2-fold higher than the growth rate in the medium without MCD (Fig. 1b). Inhibition of growth was observed at MCD concentrations over $100 \mathrm{mM}$, with full suppression at $180 \mathrm{mM} \mathrm{MCD} \mathrm{(Fig.} \mathrm{1a,} \mathrm{b).} \mathrm{The} \mathrm{data}$ were in general accordance with the colony formation on agar medium. It decreased from $2.3 \times 10^{14}$ to $3.1 \times 10^{6}$ c.f.u. $\mathrm{ml}^{-1}$ as MCD content increased from 80 to $120 \mathrm{mM}$, and no colonies appeared when the cells were exposed to $180 \mathrm{mM}$ MCD. The results evidenced the loss of cell viability under exposure to high MCD concentrations.

As shown in Fig. 2, cell aggregation increased with MCD content in the growth medium, thus indicating possible alterations of the mycobacterial cell envelope features under exposure to MCD.
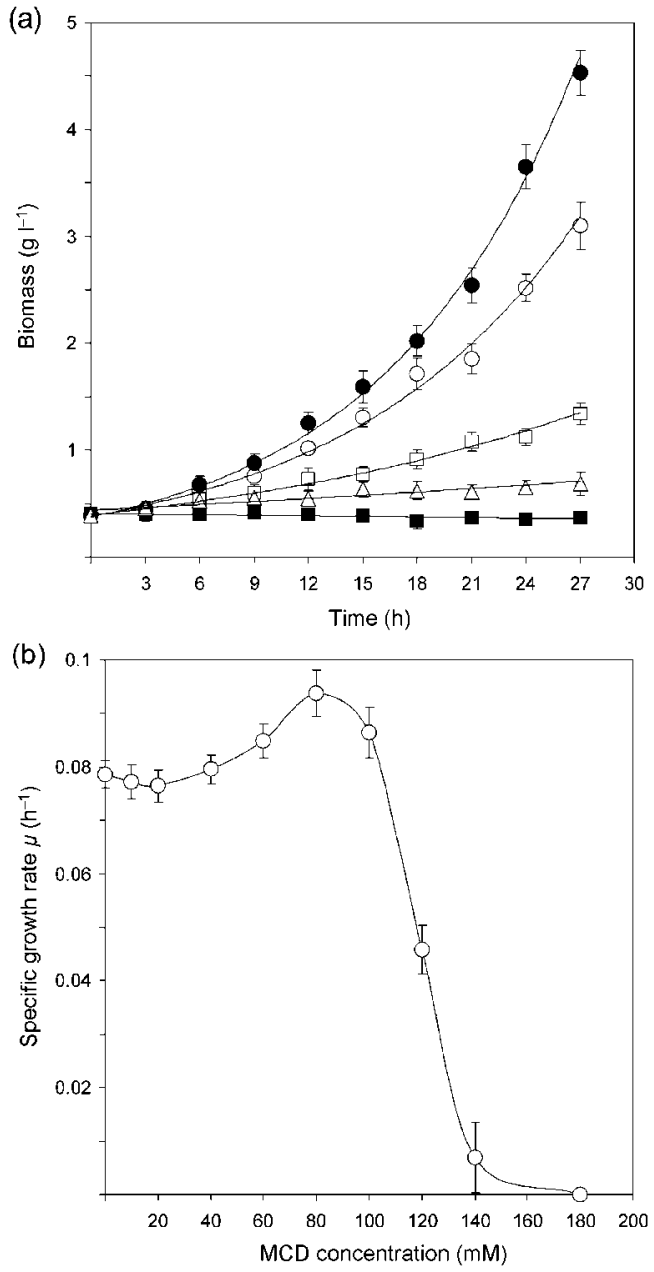

Fig. 1. Effect of MCD on the growth of Mycobacterium sp. VKM Ac-1816D on glycerol. (a) Selected growth curves for MCD concentrations: $\bigcirc, 0 \mathrm{mM}$ ○, $80 \mathrm{mM} ; \square, 120 \mathrm{mM}$;, $180 \mathrm{mM} \triangle \triangle$, control (40 mM MCD, without glycerol). (b) Specific growth rates. The strain was cultivated in the presence of MCD in medium containing $5 \mathrm{~g}_{\text {glycerol }} \mathrm{I}^{-1}$ as carbon source. Growth curves were plotted on the basis of dry biomass weight. Specific growth rates $(\mu)$ were obtained by nonlinear fitting of the model of exponential growth. Error bars represent SD.

\section{Steroid permeability estimation}

As shown in Fig. 3, the washed cells taken after growth in the presence of 20-40 mM MCD exhibited 1.6-fold higher specific sterol-transforming activities than did the cells grown without MCD. This effect can be attributed to the increase of cell envelope permeability to sitosterol and/or $\mathrm{AD}(\mathrm{D})$ due to possible MCD-mediated CW modification. The specific activity of the washed cells decreased when grown in medium supplemented with over $40 \mathrm{mM}$ MCD. Cells grown in the presence of $100 \mathrm{mM}$ MCD converted sitosterol even more slowly than did the control cells. 


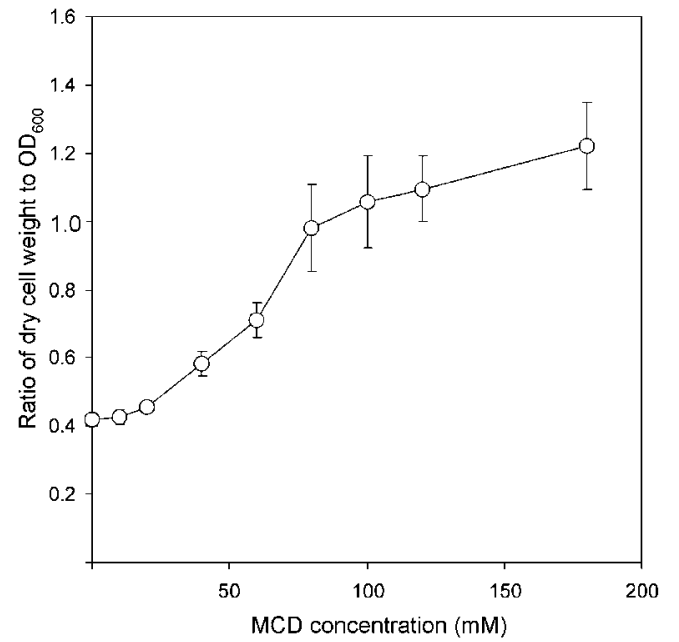

Fig. 2. Effect of MCD on cell aggregation of Mycobacterium sp. VKM Ac-1816D. Cell aggregation was estimated as the ratio of dry biomass weight to $\mathrm{OD}_{600} \pm \mathrm{SD}$ after $12 \mathrm{~h}$ of cultivation in medium containing $5 \mathrm{~g}$ glycerol $\mathrm{I}^{-1}$ as carbon source and supplemented with different concentrations of MCD.

\section{Cell-substrate interactions in the presence of MCD}

Sterols are extremely lipophilic compounds with an aqueous solubility of about $2 \mathrm{mg} \mathrm{l}^{-1}$ (Haberland \& Reynolds, 1973). However, in order to make the microbial transformations economically attractive, the bioconversion process is carried out at sterol concentrations much higher than the sterol solubility. In this heterogeneous system, the mycobacterial cells sorbed on the surface of sitosterol particles, and sitosterol uptake occurred via direct contact of the cells with this hydrophobic substrate (Atrat et al., 1991).

Microscopy observations during incubation of sitosterol with Mycobacterium sp. VKM Ac-1816D in the presence of MCD (Fig. 4a, b) showed the same character of cellsubstrate interactions as in the case of non-MCD medium (control) (Fig. 4c, d). The mycobacterial cells sorbed on the surface of sitosterol particles, forming so-called 'cellsubstrate aggregates' (Fig. 4a, b). Freeze-fracture electron micrographs of these agglomerated complexes formed both in the presence and in absence of MCD are presented in Fig. 4(d) and Fig. 4(b), respectively. The micrographs confirm tight contact between the cells and substrate and show the cells submerged into sterol particles in both cases. Thus, in the presence of MCD the sitosterol uptake possibly also took place at the direct cell-substrate contact surface.

\section{Effect of MCD on cell and CW ultrastructure}

As shown by electron microscopy, cells remained intact at MCD concentrations up to $80 \mathrm{mM}$ (Fig. 5). No MCDmediated destructive alterations of the internal cell

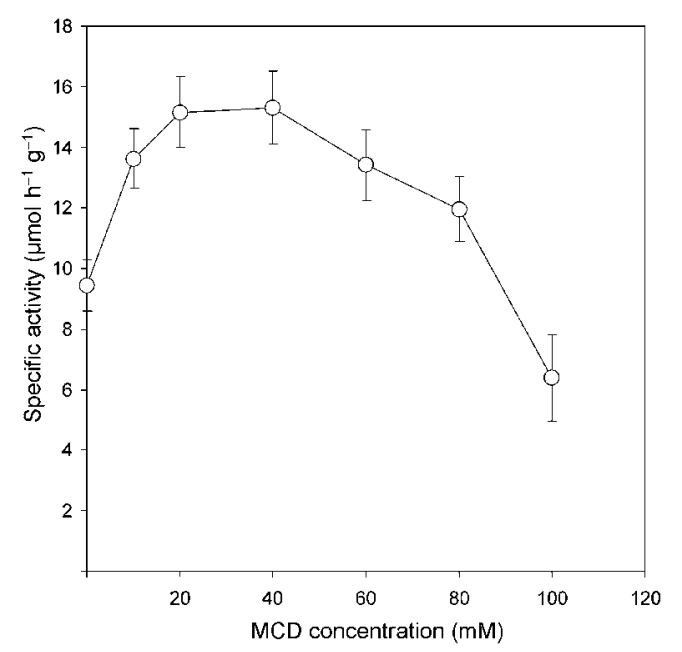

Fig. 3. Effect of MCD on the specific sterol-transforming activity of washed Mycobacterium sp. VKM Ac-1816D cells. Cells were grown on glycerol-mineral medium supplemented with different concentrations of MCD. Sterol-transforming activity was induced by $0.2 \mathrm{mM}$ sitosterol. Washed cells ( $0.33 \mathrm{~g}$ of dry cells per litre) were used for sitosterol $(10 \mathrm{mM})$ conversion in $0.05 \mathrm{M}$ potassium phosphate buffer ( $\mathrm{pH}$ 7.0). The bioconversion progress was followed by a sum of $A D$ and ADD concentrations. Specific activities were determined using linear fragments of the product accumulation time-curves (first $12 \mathrm{~h}$ ) and expressed in $\mu$ moles of $A D(D)$ formed per hour per $g$ of dry cells \pm SD. The data presented were averaged from three independent repeats.

organization were revealed (compare Fig. 5a and Fig. 5c). The cell envelope consisted of a cytoplasmic membrane $(\mathrm{CPM})$, an electron-dense internal layer (IL), an electrontransparent layer (TL) and a low-contrasting outer layer $(\mathrm{OL})$. The structure generally corresponded to that described for other mycobacteria and related actinobacteria (Puech et al., 2001, Etienne et al., 2002).

Application of ruthenium red, a stain that strongly reacts with the surface of mycobacteria (Puech et al., 2001), allowed clearer visualization of the TL and the OL (Fig. 5d, e). The TL constitutes the hydrophobic domain of the CW and is traditionally considered to consist of mycolic acids covalently bound to arabinogalactan (Wang et al., 2000; Puech et al., 2001). No disappearance of this layer was observed in MCD-grown cells (Fig. 5e). As shown in Fig. 5(d), tight surface contact of TLs of different cells was observed, thus suggesting the role of hydrophobic interactions in cell aggregation in the absence of MCD.

The outermost OL is typical for corynebacteria and may contain carbohydrates, glycolipids and proteins (Puech et al., 2001). In the case of cells grown in the presence of MCD $(80 \mathrm{mM})$, the OL was found to be two- to threefold thicker than the OL within the cells grown without MCD (Fig. 5e). 

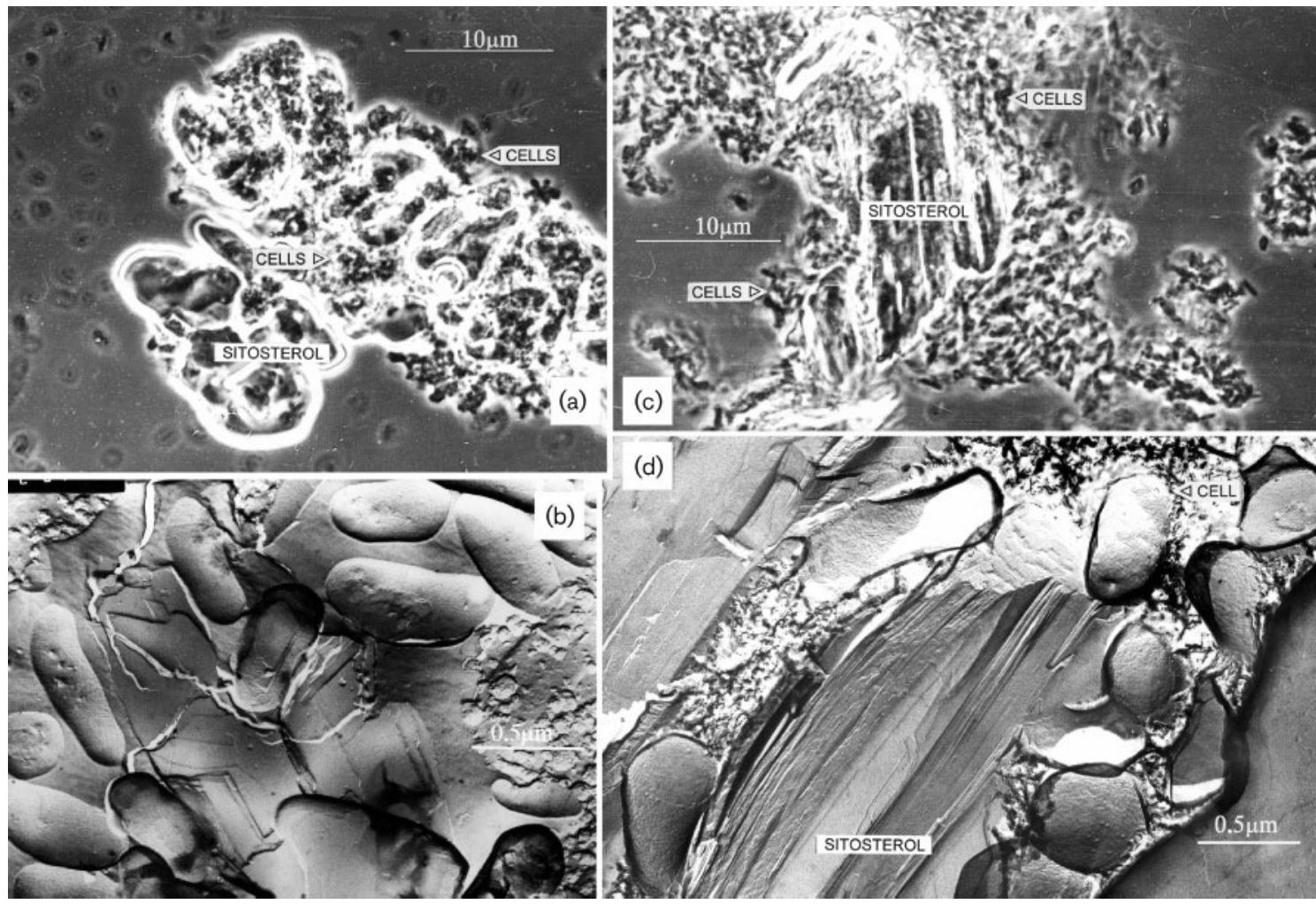

Fig. 4. Cell-substrate interaction of Mycobacterium sp. VKM Ac-1816D during sitosterol bioconversion: (a, c) light microscopy; (b, d) freeze-fracturing; $(a, b)$ bioconversion in the absence of MCD (control); $(c, d)$ bioconversion in the presence of MCD (40 mM).

The appearance of amorphous granular material on the surface of the cells grown in the presence of MCD was revealed by both transmission (Fig. 6a, c) and freezefracturing electron microscopy (Fig. 6b). In addition, the exfoliation of the outermost CW layers (Fig. 6d) and accumulation of low-contrasted amorphous material with membrane-like structures outside the cells (Fig. 6e) were observed. This material differed from the filamentous and rope-like structures budding from the cell surface of the cells grown in the absence of MCD (Fig. 5b). Altogether, the micrographs illustrate sharp MCD-mediated distinctions in the outermost cell surface structure and the environment.

\section{Effect of MCD on the CW composition of mycobacteria}

The CW composition of cells grown in the presence of $40 \mathrm{mM}$ MCD was compared with that of cells grown without MCD.

Mycolic acids. As shown in Fig. 7, the same mycolic acid components were observed in the cells grown with and without MCD, which showed no MCD-mediated qualitative changes. A distinct shift in the content of particular components was revealed: the proportion of ketomycolates, methoxymycolates, 2-eicosanol and homologues in the MCD-grown cells increased, while the content of carboxymycolates decreased.

The mycolic acid patterns of the post-growth media obtained after cultivation of mycobacteria with or without MCD profoundly differed. A substantial MCD-mediated increase of mycolates, especially $\alpha$-mycolates and 2eikosanol and homologues, was observed outside the cells.

Extractable lipids. The quantity of fatty acid components in the post-culture medium of MCD-grown cells was higher than that in the control (Fig. 7). This was in accordance with lower overall content of non-covalently bound lipids extracted from MCD-grown cells (Fig. 8).

GC analysis of the cellular lipids showed a moderate MCDmediated increase in saturated fatty acids with less than 27 carbon units, while the amount of fatty acids with 28 or more carbon units, as well as unsaturated fatty acids, decreased drastically (Table 1).

The fatty acid profiles of the post-culture medium samples did not correspond to those of the whole-cell lipids. It showed that the selective fatty acids appeared in the environment most probably as a result of their release into 


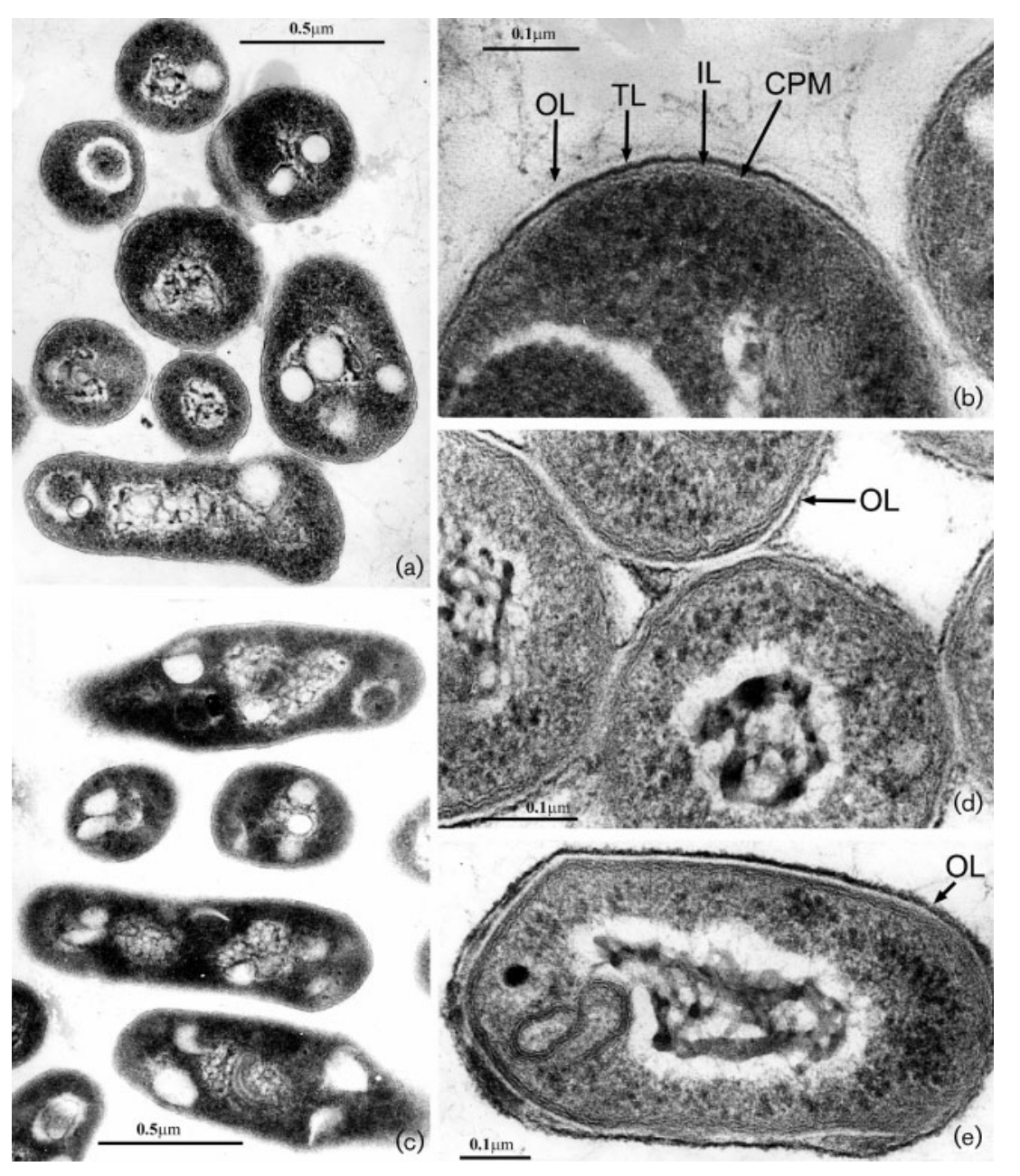

Fig. 5. Effect of MCD on the ultrastructure of Mycobacterium sp. VKM Ac-1816D: (a) cells grown in the absence of MCD (control); (b) close-up of the cell envelope (control); (c, e) cells grown in the presence of MCD $(80 \mathrm{mM})$; (d) control for cell-cell interactions; ( $d, e)$ cells contrasted with ruthenium red. CPM, Cytoplasmic membrane; CW, cell wall; IL, electron-dense internal layer; OL, low-contrasting outer layer; TL, electron-transparent layer. the medium rather than cell lysis. A similar effect was described for $M$. vaccae cells exposed to polycations (Korycka-Machala et al., 2001).

The short-chain fatty acids (up to $\mathrm{C}_{16: 0}$ ) accumulated in the environment in higher concentrations than those detected in whole-cell lipids, thus indicating that these components were easily removed from the cell surface. Their elevated discharge was observed in the presence of MCD.

A markedly higher level of saturated fatty acids $\left(\mathrm{C}_{22}: 0^{-}\right.$ $\mathrm{C}_{27: 0}$ ) in the post-culture medium compared with that in whole cells was observed in the absence of MCD, while MCD-containing post-culture medium contained threefold less saturated fatty acids $\left(\mathrm{C}_{22}: 0-\mathrm{C}_{27}: 0\right)$.

The greater accumulation of unsaturated fatty acids outside the cells, especially $\mathrm{C}_{11: 1}$, octadecenoic acid $\left(\mathrm{C}_{18: 1}\right)$ and a long-chain mycolic acid $\left(\mathrm{C}_{\mathrm{i} 28: 1}\right)$, could be attributed to the enhanced release of free lipids from the $\mathrm{CW}$ under exposure to MCD.

Carbohydrate composition. Analysis of the acid hydrolysis products of the lyophilized cells showed their carbohydrate composition (Table 2). Arabinose, mannose, glucose and galactose were the major structural polysaccharide components in cells grown both with and without MCD. A striking discrepancy was observed in the quantity of the carbohydrates. The total amount of carbohydrates was remarkably higher in cells grown in the presence of MCD (Table 2). The results indicated preserved intactness of the arabinogalactan/lipoarabinomannan skeleton of the CW after exposure of cells to subinhibitory concentrations of MCD.

Protein secretion and extracellular steroid-transforming activity. On average, the protein content in the post-culture medium of MCD-grown cells increased by a factor of 2.7. The activity of the extracellular 3-hydroxysteroid oxidase rose 3.2-fold (Table 3). The presence of extracellular 3ketosteroid-1-dehydrogenase, 1-ene-reductase and 17hydroxysteroid dehydrogenase activities was also revealed, similar to that observed in a non-MCD medium (Nikolayeva et al., 2004).

\section{DISCUSSION}

Bioprocess intensification by CDs is usually interpreted in the light of CD-mediated solubilization of hydrophobic substrates and/or products, or decrease of the toxicity of a 


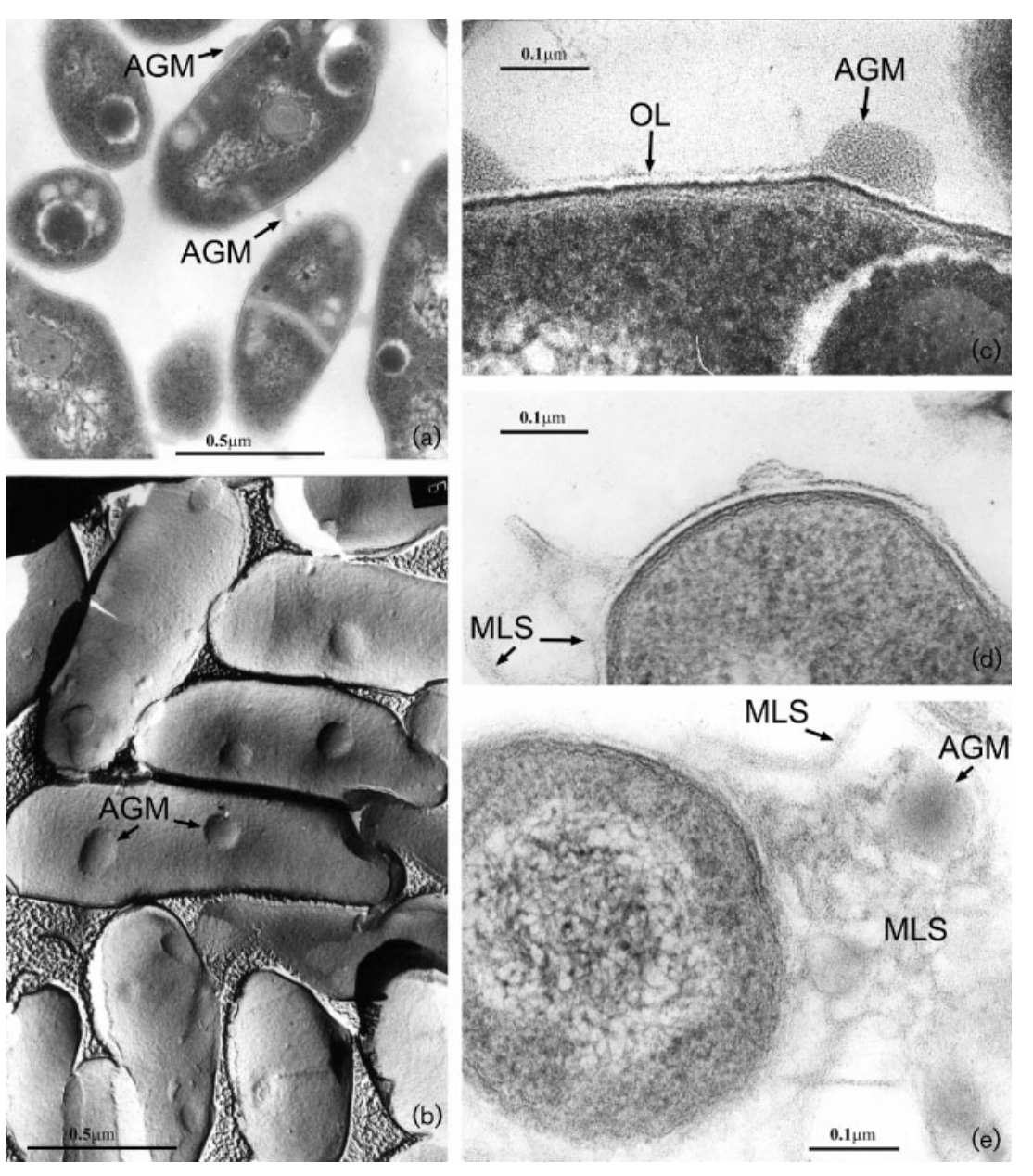

Fig. 6. MCD-mediated alterations in the cell envelopes: ultrathin sections $(\mathrm{a}, \mathrm{c})$ and freezefracturing (b) showed amorphous granular material (AGM) on the cell surface of MCDgrown cells; $(d, e)$ the membrane-like structures (MLS) outside the cells (ultrathin sections). MCD concentration in the nutrient medium was $80 \mathrm{mM}$. compound due to the formation of a complex with CD; i.e. it is focused on the effect of the CDs on the compounds, but not on the biocatalyst itself. Very few papers have been published on the $\mathrm{CD}$ interaction with microbial cells (Jadoun \& Bar, 1993; Greenberg-Ofrath et al., 1993). In this work, we first investigated the effect of MCD on steroltransforming mycobacteria.

The strain Mycobacterium sp. VKM Ac-1816D (preliminarily identified as $M$. vaccae) was unable to utilize MCD as a carbon source, similarly to other actinobacteria. A moderate stimulation of the growth on glycerol was observed in the presence of subinhibitory MCD concentrations. We suggest that this effect can be attributed to increased CW permeability for glycerol or other hydrophilic nutrients due to possible CW modification.

The inhibition of cell growth and decrease of steroltransforming activity at MCD concentrations over $80 \mathrm{mM}$ possibly reflected severe damage to the $\mathrm{CW}$, resulting in the loss of cell integrity and viability. The growth suppression by dimethylated $\beta$-CD (Dimeb) was demonstrated earlier for Mycoplasma capricolum and Rhodococcus erythropolis (Greenberg-Ofrath et al., 1993; Jadoun \& Bar, 1993).
Electron microscopy observations did not reveal any destruction of intracellular organization of mycobacterial cells grown in the presence of subinhibitory MCD concentrations. This was in agreement with preserved cell viability and CW basal arabinogalactan skeleton. As shown, the integrity of the mycolyl-arabinogalactan structure is important for the sterol side-chain degradation ability of mycobacteria and related micro-organisms (Sedlaczek et al., 1994).

The heterophase character of cell interaction with solid substrate particles in the presence of MCD was similar to that described for non-MCD medium (Atrat et al., 1991). It is in accordance with the high adhesiveness of mycobacterial cells grown in the presence of MCD. It is probable that only the small outermost surface of the sterol particles solubilized in the presence of MCD.

CDs were shown to function at the level of small lipophilic molecules, and neither MCD nor its inclusion complexes with sitosterol would penetrate through intact $\mathrm{CW}$ and cytoplasmic membrane into the cell, due to their large sizes (Hesselink et al., 1989). The mechanism whereby the CD complex interacts with the microbial cell was suggested in 


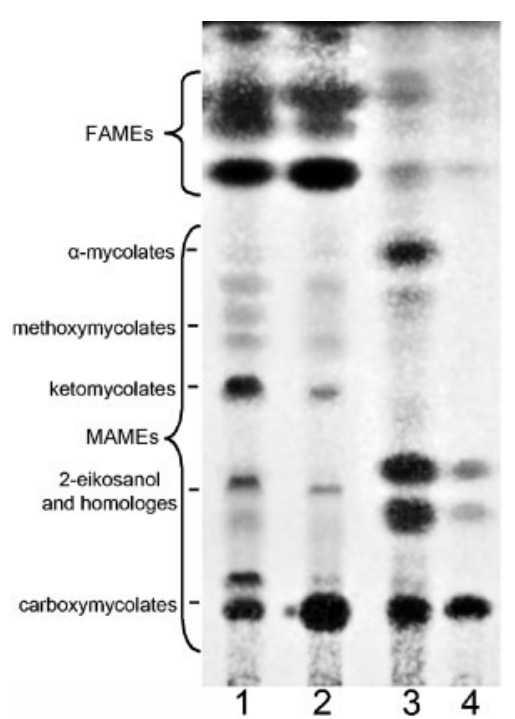

Fig. 7. Effect of MCD on total lipid profile of whole-cell and postculture medium of Mycobacterium sp. VKM Ac-1816D. MAMEs and FAMEs were obtained from the lyophilized samples of cells and post-culture medium. The purified and dried preparations were dissolved in ethyl acetate and analysed by TLC. The plate was developed in hexane/ethyl acetate (94:6, v/v), sprayed with $10 \%$ $(\mathrm{w} / \mathrm{v})$ phosphomolybdic acid in ethanol and heated to $180{ }^{\circ} \mathrm{C}$. Lanes 1 and 2, cells grown in the presence or absence of MCD, respectively; lanes 3 and 4, post-culture media obtained after cell growth in the presence or absence of MCD, respectively.

the study of cholesterol to cholestenone conversion by $R$. erythropolis (Jadoun \& Bar, 1993). The complex-bound form of sterol was proposed to 'adsorb' on the CW and dissociate, thus releasing the 'free' (non-complex) sterol. The 'free' sterol molecule may permeate through the CW

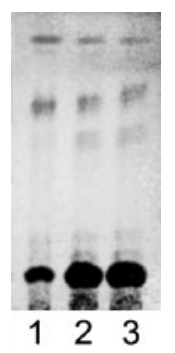

Fig. 8. Effect of MCD on Mycobacterium sp. VKM Ac-1816D free lipids. Lipids were extracted from samples of lyophilized cells (100 mg each) with $50 \mathrm{ml}$ chloroform/methanol (2:1, v/v). The purified and dried preparations were dissolved in ethyl acetate and analysed by TLC. The TLC plate was developed five times in hexane/ethyl acetate $94: 6(\mathrm{v} / \mathrm{v})$; spots were visualized by spraying with $10 \%(\mathrm{w} / \mathrm{v})$ phosphomolybdic acid in ethanol and heating to $180^{\circ} \mathrm{C}$. Lanes: 1 , cells grown in the presence of MCD; 2 and 3 , cells grown without MCD (controls). into the cell by the 'lipid' pathway. As is known, the sidechain degradation of sterols is an intracellular process catalysed by cytoplasmic enzymes (Szentirmai, 1990). Sterol oxidation products [i.e. $\mathrm{AD}(\mathrm{D})$ ] can cross the $\mathrm{CW}$ by the similar reverse pathway and, once outside the cells, can interact with MCD, forming soluble inclusion complexes (Khomutov et al., 2002).

Natural or chemically modified CDs can interact with cells by means of their complexing ability and/or their surface activity. These properties of MCDs can result in the facilitation of outer-surface lipid and protein leakage from the microbial CW. Indeed, we observed MCD-mediated decrease of non-covalently bound lipid content in mycobacterial cells and the enhanced release of some fatty acids, mycolic acids and proteins from the cells. The data evidenced the disorganization of the lipid bilayer, and of the outermost leaflet of the bilayer in particular. This was in accordance with electron microscopy data on MCDmediated exfoliation of the outer cell-surface layers and accumulation of amorphous material outside the cells. The chemical structure of this material was not established, but we assume that in addition to the components which are normally present in the mycobacterial cell environment, it can contain discharged proteins and mycolic and fatty acids. Based on the high affinity of MCD to hydrophobic fatty acids, the formation of inclusion complexes of the released CW components with MCD can be proposed. Proteins normally hardly fit in a CD cavity, while CD interactions with certain single amino acids are possible (Matsuyama et al., 1987). The inclusion complexes of steroids with MCD can be inaccessible for enzyme attack (Khomutov et al., 2001). However, the interaction of sterol-MCD complexes with extracellular or CW-associated cholesterol oxidase cannot be fully excluded.

The permeability and fluidity of the mycobacterial CW was shown to strongly depend on the structure of mycolic acids (Liu et al., 1996). For example, the inability of mutant Mycobacterium tuberculosis $\mathrm{H} 37 \mathrm{Rv}$ to synthesize keto- and methoxymycolates resulted in lower rates of chenodeoxycholate and glycerol uptake (Dubnau et al., 2000). In this study, we did not carry out a careful quantitative mycolic acid estimation, but the results indicate the evidence of MCD-mediated changes in the proportion of particular mycolates in whole-cell and post-culture medium methanolysates. The higher content of ketomycolates, methoxymycolates, 2-eicosanol and homologues and lower content of carboxymycolates in whole cells, as well as the appearance of significant amounts of $\alpha$-mycolates, 2 eicosanol and homologues in the post-culture medium, may reflect the partial disorganization of the inner leaflet of the lipid bilayer in cells grown in the presence of MCD. These alterations may influence the fluidity and permeability of the leaflet.

Recently, we reported the presence of extracellular sterol oxidase in fast-growing sterol-transforming $M$. vaccae VKM Ac-1815D (Nikolayeva et al., 2004). The enzyme 
Table 1. Effect of MCD on fatty acid composition of free lipid fractions of Mycobacterium sp. VKM Ac-1816D

Cells were grown on sitosterol-containing glycerol medium supplemented with $40 \mathrm{mM} \mathrm{MCD}$ (SM) or without MCD (S). The lipids were extracted from samples of lyophilized cells and supernatants; the extracts were separated by filtration, evaporated, methanolysed and analysed by GC. The values were obtained from three independent measurements, the standard deviations were less than $8 \%$ of the mean.

\begin{tabular}{|c|c|c|c|c|}
\hline \multirow[t]{2}{*}{ Fatty acid } & \multicolumn{2}{|c|}{ Whole-cell lipids (nmol mg ${ }^{-1}$ ) } & \multicolumn{2}{|c|}{ Post-culture medium $\left(\mathrm{nmol} \mathrm{mg}^{-1}\right)$} \\
\hline & SM & $S$ & SM & $S$ \\
\hline $11: 0$ & - & - & 4.54 & - \\
\hline i12 : 0 & 0.55 & - & 4.42 & 5.4 \\
\hline $12: 0$ & 0.78 & - & 6.91 & - \\
\hline $14: 0$ & 1.82 & 1.56 & - & - \\
\hline $\mathrm{i} 14: 0$ & - & - & 7.13 & - \\
\hline di-OH $15: 0$ & - & - & 5.73 & 3.95 \\
\hline i16 : 0 & 3.75 & 2.88 & - & - \\
\hline $16: 0$ & 8.86 & 7.01 & 9.29 & 2.9 \\
\hline Mel17 : 0 & 0.42 & 0.41 & - & - \\
\hline i17 : 0 & 0.44 & - & - & - \\
\hline $18: 0$ & 1.7 & 1.11 & - & - \\
\hline i19 : 0 & 0.62 & 0.47 & - & - \\
\hline i20 : 0 & 2.28 & 1.96 & - & - \\
\hline $22: 0-27: 0$ & 7.88 & 7.27 & 21.11 & 69.92 \\
\hline $28: 0$ & 1.7 & 10.43 & - & - \\
\hline Me29: 0 & 0.5 & 3.99 & - & - \\
\hline Unsaturated & 8.74 & 20.00 & 12.48 & 2.63 \\
\hline $11: 1$ & 0.42 & - & 24.3 & - \\
\hline $16: 1$ & 4.46 & 2.93 & - & - \\
\hline $17: 1$ & 0.70 & - & - & - \\
\hline $18: 1 \mathrm{~W} 9 \mathrm{c}$ & 8.29 & 5.76 & 4.97 & - \\
\hline $18: 1 \mathrm{~W} 9 \mathrm{t}$ & 13.25 & 9.34 & 4.11 & - \\
\hline i19 : 1 & 0.55 & 1.78 & - & - \\
\hline $27: 1$ & 1.34 & 1.59 & - & - \\
\hline i28: 1 & 2.4 & 5.15 & 17.82 & 8.36 \\
\hline
\end{tabular}

Table 2. Effect of MCD on the CW polysaccharide composition of Mycobacterium sp. VKM Ac1816D

Samples of lyophilized cells were hydrolysed by trifluoroacetate at $105{ }^{\circ} \mathrm{C}$ and analysed by ion-exchange chromatography. The values were obtained from three independent measurements; the standard deviations were less than $10 \%$ of the mean.

\begin{tabular}{|c|c|c|c|c|}
\hline \multirow[t]{2}{*}{$\begin{array}{l}\text { Carbohydrate } \\
\text { component }\end{array}$} & \multicolumn{2}{|c|}{$\begin{array}{l}\text { Cells grown in the presence of } \\
\text { sitosterol and MCD }\end{array}$} & \multicolumn{2}{|c|}{$\begin{array}{l}\text { Cells grown in the presence of } \\
\text { sitosterol (control) }\end{array}$} \\
\hline & $\mu \mathrm{g} \mathrm{mg}^{-1}$ & $\%$ & $\mu \mathrm{g} \mathrm{mg}^{-1}$ & $\%$ \\
\hline Cellulose & 8.28 & 6.8 & 0.28 & 1.2 \\
\hline Maltose & 8.85 & 7.3 & 0.95 & 4.1 \\
\hline Rhamnose & 0.50 & 0.4 & 0.27 & 1.2 \\
\hline Ribose & 5.17 & 4.2 & 0.98 & 4.3 \\
\hline Mannose & 22.73 & 18.6 & 3.63 & 15.8 \\
\hline Fructose & 6.04 & 5.0 & - & - \\
\hline Arabinose & 33.59 & 27.6 & 7.14 & 31.0 \\
\hline Galactose & 15.34 & 12.6 & 4.67 & 20.3 \\
\hline Glucose & 21.4 & 17.6 & 5.10 & 22.2 \\
\hline Total & 121.9 & 100 & 23.02 & 100 \\
\hline
\end{tabular}


Table 3. Effect of MCD on protein secretion and extracellular 3-hydroxysteroid oxidase activity of Mycobacterium sp. VKM Ac1816D

Cells were grown on sitosterol-containing glycerol medium supplemented with $40 \mathrm{mM}$ MCD (SM) or without MCD (S) (control). Post-culture medium samples were concentrated with Centricon Plus cartridges. The activity of the 3-hydroxysteroid oxidase was measured at $37{ }^{\circ} \mathrm{C}$ and $\mathrm{pH} 6.8$ as described by Sojo et al. (1997) and Nikolayeva et al. (2004). One unit of activity (U) was defined as the amount of enzyme that converted $1 \mu$ mol DHEA per min at $37^{\circ} \mathrm{C}$.

\begin{tabular}{|lcccc|}
\hline $\begin{array}{l}\text { Cell-free cultivation } \\
\text { broth }\end{array}$ & $\begin{array}{c}\text { Total volume } \\
(\mathbf{m l})\end{array}$ & $\begin{array}{c}\text { Total protein } \\
(\boldsymbol{\mu g})\end{array}$ & $\begin{array}{c}\text { Total activity } \\
\left(\mathbf{U} \times \mathbf{1 0}^{-\mathbf{3}}\right)\end{array}$ & $\begin{array}{c}\text { Specific activity } \\
\left(\mathbf{U} \boldsymbol{\mu g}^{-\mathbf{1}}\right)\end{array}$ \\
\hline SM & 50 & 560 & 18.5 & 33 \\
S & 50 & 230 & 5.8 & 25 \\
\hline
\end{tabular}

catalyses the first reaction of sterol oxidation, the modification of 3 - $\beta$-ol-5-ene to the 3-keto-4-ene moiety of the steroidal A-ring. The enzyme was found to be weakly associated with the CW, located on the outer cell surface and released into the environment by mild cell treatment with the non-ionic detergent Triton X-100. The enzyme activity was also detected in the post-culture medium of non-treated cells.

In this work, a considerable (more than threefold) increase in enzyme activity in the post-culture medium was observed in cells grown in the presence of MCD. The sterol oxidase weakly associated with the cell surface was probably excreted into the environment in response to MCD. The leakage of cellular proteins and cholesterol oxidase was earlier shown for $R$. erythropolis cells exposed to Dimeb (Jadoun \& Bar, 1993).

The analyses of mycolic acids, extractable lipids and secreted proteins evidenced that MCD mostly affected the composition of the lipid bilayer, and the outermost leaflet of the bilayer in particular. This leaflet was shown to hinder the access of sterols to the enzyme system inside the cell (Sedlaczek et al., 1994). Its MCD-mediated disorganization possibly resulted in increased CW permeability for both substrate and products, thus providing an increase in the yield of $\mathrm{AD}$ and $\mathrm{ADD}$.

In conclusion, the structure and features of the cell envelope were altered by exposure of mycobacteria to MCD. The structural alterations included disorganization of the CW outer lipid bilayer, destruction of the outermost leaflet of the bilayer, full or partial removal from the CW of non-covalently bound lipids and associated proteins, and shifts in the mycolic acid composition, thus enhancing the permeability of the CW. These alterations may result in the enhancement of growth and sterol-transforming activity and provide the constituents of a multiple mechanism of MCD-mediated intensification of sterol bioconversion by mycobacteria.

\section{ACKNOWLEDGEMENTS}

This work was partly supported by RFBR grant 04-04-49605. We thank Dr Olga Egorova, Dr Valentina Ilchenko and Dr Nina Zelenkova for valuable advice and assistance with this work.

\section{REFERENCES}

Atrat, P., Hosel, P., Richter, W., Meyer, H. W. \& Hörhold, C. (1991). Interactions of Mycobacterium fortuitum with solid substrate particles. J Basic Microbiol 31, 413-422.

Bendinger, B., Rijnaarts, H. H. M., Altendorf, K. \& Zehnder, A. J. B. (1993). Physicochemical cell surface and adhesive properties of coryneform bacteria related to the presence and chain length of mycolic acids. Appl Environ Microbiol 59, 3973-3977.

Borrego, S., Niubo, E., Ancheta, O. \& Espinosa, M. E. (2000). Study of the microbial aggregation in Mycobacterium using image analysis and electron microscopy. Tissue Cell 32, 494-500.

Bradford, M. M. (1976). A rapid and sensitive method for the quantitation of microgram quantities of protein utilizing the principle of protein-dye binding. Anal Biochem 72, 248-254.

Brennan, P. J. \& Nikaido, H. (1995). The envelope of mycobacteria. Annu Rev Biochem 64, 29-63.

Chatterjee, D. (1997). The mycobacterial cell wall: structure, biosynthesis and sites of drug action. Curr Opin Chem Biol 1, 579-588.

Daffe, M. \& Draper, P. (1998). The envelope layers of mycobacteria with reference to their pathogenicity. Adv Microb Physiol 39, 131-203.

Donova, M. V., Dovbnya, D. V. \& Koshcheyenko, K. A. (1996). Modified CDs-mediated enhancement of microbical sterol sidechain degradation. In Proceedings of the eighth International Symposium on Cyclodextrins, pp. 527-530. Dordrecht: Kluwer Publishers.

Draper, P. (1982). The anatomy of mycobacteria. In The Biology of the Mycobacteria, vol. 1, part 1, pp. 9-49. Edited by C. Ratledge \& J. Stanford. London/New York: Academic Press.

Dubnau, E., Chan, J., Raynaud, C., Mohan, V. P., Laneelle, M. A., Yu, K., Quemaard, A., Smith, I. \& Daffe, M. (2000). Oxygenated mycolic acids are necessary for virulence of Mycobacterium tuberculosis in mice. Mol Microbiol 36, 630-637.

Etienne, G., Villeneuve, C., Billman-Jacobe, H., Astarie-Dequeker, C., Dupont, M.-A. \& Daffe, M. (2002). The impact of the absence of glycopeptolipids on the ultrastructure, cell surface and cell wall properties, and phagocytosis of Mycobacterium smegmatis. Microbiology 148, 3089-3100.

Fromming, K.-H. \& Szejtly, J. (1993). Cyclodextrins in pharmacy. In Topics in Inclusion Science, vol. 5, pp. 1-81. Edited by J. E. D. Davies. Dordrecht: Kluwer Academic Publishers.

Greenberg-Ofrath, N., Terespolosky, Y., Kahane, Y. \& Bar, R. (1993). Cyclodextrins as carriers of cholesterol and fatty acids in cultivation of mycoplasmas. Appl Environ Microbiol 59, 547-551.

Haberland, M. E. \& Reynolds, J. A. (1973). Self-association of cholesterol in aqueous solution. Proc Natl Acad Sci U S A 70, 2313-2316. 
Hesselink, P. G. M., van Vliet, S., de Vries, H. \& Witholt, B. (1989). Optimization of steroid side-chain cleavage by Mycobacterium sp. in the presence of cyclodextrins. Enzyme Microb Technol 11, 398-404.

Jadoun, J. \& Bar, R. (1993). Microbial transformations in a cyclodextrin medium. Part 4. Enzyme vs microbial oxidation of cholesterol. Appl Microbiol Biotechnol 40, 477-482.

Jarlier, V. \& Nikaido, H. (1994). Mycobacterial cell wall: structure and role in natural resistance to antibiotics. FEMS Microbiol Lett 123, 11-18.

Khomutov, S. M., Sukhodoloskaya, G. V. \& Donova, M. V. (2001). Cyclodextrin stabilization of steroid against microbial degradation. Biological Journal of Armenia (Special issue Cyclodextrin) 53, 194200.(in Russian)

Khomutov, S. M., Sidorov, I. A., Dovbnya, D. V. \& Donova, M. V. (2002). Estimation of cyclodextrin affinity to steroids. J Pharm Pharmacol 54, 617-622.

Korycka-Machala, M., Ziolkowski, A., Rumijowska-Galewicz, A., Lisowska, K. \& Sedlaczek, L. (2001). Polycations increase the permeability of Mycobacterium vaccae cell envelopes to hydrophobic compounds. Microbiology 147, 2769-2781.

Lacave, C., Lanelle, M. A. \& Lanelle, G. (1990). Mycolic acid synthesis by Mycobacterium aurum cell free extracts. Biochim Biophys Acta 1042, 315-323.

Lisowska, K., Korycka, M., Hadlaw-Klimaszewska, O., Ziolkowski, A. \& Sedlaczek, L. (1996). Permeability of mycobacterium cell envelopes to sterols: peptidoglycan as the diffusion barrier. J Basic Microbiol 36, 407-419.

Liu, J., Barry, C. E., III, Besra, G. S. \& Nikaido, H. (1996). Mycolic acid structure determines the fluidity of the mycobacterial cell wall. J Biol Chem 271, 29545-29551.

Matsuyama, K., El-Gizawy, S. \& Perrin, J. (1987). Thermodynamics of binding of amino acids to $\alpha$-, $\beta$ - and $\gamma$-cyclodextrins. Drug Dev Ind Pharm 13, 2687-2689.

Minnikin, D. E. (1991). Chemical principles in the organization of the lipid components in the mycobacterial cell envelope. Res Microbiol 142, 423-427.

Nikaido, H. \& Jarlier, V. (1991). Permeability of the mycobacterial cell wall. Res Microbiol 142, 437-443.

Nikolayeva, V. M., Egorova, O. V., Dovbnya, D. V. \& Donova, M. V. (2004). Extracellular $3 \beta$-hydroxysteroid oxidase of Mycobacterium vaccae VKM Ac-1815 D. J Steroid Biochem Mol Biol 91, 79-85.
Puech, V., Chami, M., Lemassu, A., Laneelle, M.-A., Schiffler, B., Gounon, P., Bayan, N., Benz, R. \& Daffe, M. (2001). Structure of the cell envelope of corynebacteria: importance of the non-covalently bound lipids in the formation of the cell wall permeability barrier and fracture plane. Microbiology 147, 1365-1382.

Ratledge, C. (1982). Lipids: cell composition, fatty acid biosynthesis. In The Biology of the Mycobacteria, vol. 1, part 1, pp. 53-93. Edited by C. Ratledge \& J. Stanford. London \& New York: Academic Press.

Reynolds, E. S. (1963). The use of lead citrate at high $\mathrm{pH}$ as an electron-opaque stain in electron microscopy. J Cell Biol 17, 208-213.

Rumijowska, A., Lisowska, K., Ziolkovski, A. \& Sedlaczek, L. (1997). Transformation of sterols by Mycobacterium vaccae: effects of lecithin on the permeability of cell envelopes to sterols. World J Microbiol Biotechnol 13, 89-95.

Schimz, K.-L., Irrgang, K. \& Overhoff, B. (1985). Trehalose, a cytoplasmic reserve disaccharide of Cellulomonas sp. DSM20108: its identification, carbon-source-dependent accumulation, and degradation during starvation. FEMS Microbiol Lett 30, 165-169.

Sedlaczek, L., Gorminski, B. M. \& Lisowska, K. (1994). Effect of inhibitors of cell envelope synthesis on $\beta$-sitosterol sidechain degradation by Mycobacterium sp. NRRL MB 3683. J Basic Microbiol 34, 387-399.

Sedlaczek, L., Lisowska, K., Korycka, M., Rumijowska, A., Ziolkowski, A. \& Dlugonski, J. (1999). The effect of cell wall components on glycine-enhanced sterol side chain degradation to androstene derivatives by mycobacteria. Appl Microbiol Biotechnol 52, 563-571.

Sojo, M., Bru, R., Lopez-Molina, D., Garcia-Carmona, F. \& Argulles, J.-C. (1997). Cell-linked and extracellular cholesterol oxidase activities from Rhodococcus erythropolis. Isolation and physiological characterization. Appl Microbiol Biotechnol 47, 583-589.

Szejtli, J. (1997). Utilization of cyclodextrins in industrial products and processes. J Mater Chem 7, 575-587.

Szentirmai, A. (1990). Microbial physiology of side chain degradation of steroids. J Ind Microbiol Biotechnol 6, 101-115.

Trias, J. \& Benz, R. (1994). Permeability of the cell wall of Mycobacterium smegmatis. Mol Microbiol 14, 283-290.

Trias, J., Jarlier, V. \& Benz, R. (1992). Porins in the cell wall of mycobacteria. Science 258, 1479-1481.

Wang, L., Slayden, R. A., Barry, C. E., III \& Liu, J. (2000). Cell wall structure of a mutant of Mycobacterium smegmatis defective in the biosynthesis of mycolic acids. J Biol Chem 275, 7224-7229.

Edited by: T. Nihira 